\title{
Prevalence of ankylosing spondylitis in a Chinese population: a systematic review and meta-analysis
}

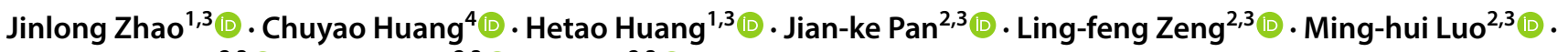 \\ Gui-hong Liang ${ }^{2,3}$ (D) Wei-yi Yang ${ }^{2,3}$ (1) $\cdot$ Jun Liu Li $^{2,3}$
}

Received: 30 December 2019 / Accepted: 13 February 2020 / Published online: 3 March 2020

(c) The Author(s) 2020

\begin{abstract}
Ankylosing spondylitis (AS) is a common inflammatory rheumatic disease that affects the axial skeleton. In this study, we systematically reviewed Chinese AS epidemiological studies from the past 15 years to elucidate its prevalence and provide scientific data for China's health care system. AS epidemiological research in China was summarized by conducting a literature review. A review and statistical analysis of the literature on the epidemiology of AS in mainland China published from May 2005 to May 2019 were performed via a meta-analysis. We calculated the prevalence of AS and analysed differences by sex, region, and population source using STATA12.0 software. Eleven papers including 122,558 subjects from mainland China were included. Over the past 15 years, the total prevalence of AS in mainland China was $0.29 \%$ (95\% CI $0.22-0.35 \%$ ), ranging from $0.42 \%$ (95\% CI $0.31-0.52 \%$ ) in males to $0.15 \%$ (95\% CI $0.13-0.18 \%$ ) in females; the difference in the prevalence of AS by sex was statistically significant $(P<0.001)$. The prevalence of AS in both southern and northern China was $0.31 \%$ (95\% CI $0.21-0.42 \%$ and $0.21-0.40 \%$, respectively), with no significant difference noted $(P=0.816>0.005)$. The prevalence of AS in Chinese military populations was $0.27 \%$ (95\% CI $0.09-0.45 \%$ ), and in community populations, it was $0.29 \%$ (95\% CI $0.23-0.35 \%$ ). There was no statistically significant difference in the prevalence of AS by sampling resource $(P=0.115>0.005)$. The prevalence of AS in China was $0.29 \%$ and continues to increase. Sex differences in its prevalence were identified; the prevalence rate was 2.8 times higher in males than in females. Epidemiologists in China should formulate precise scientific investigations to provide additional authoritative epidemiological data for the prevention and treatment of AS.
\end{abstract}

Keywords China $\cdot$ Ankylosing spondylitis $\cdot$ Epidemiology $\cdot$ Prevalence $\cdot$ Systematic review $\cdot$ Meta-analysis

$\begin{array}{ll}\text { Abbreviations } \\ \text { AS } & \text { Ankylosing spondylitis } \\ \text { axSpA } & \text { Axial spondyloarthritis } \\ \text { nr-axSpA } & \text { Non-radiographic } \\ \text { QOL } & \text { Quality of life } \\ \text { RCTs } & \text { Randomized clinical trials }\end{array}$

Jinlong Zhao, Chuyao Huang and Hetao Huang have contributed equally to this work.

Electronic supplementary material The online version of this article (https://doi.org/10.1007/s00296-020-04537-0) contains supplementary material, which is available to authorized users.

Jun Liu

liujun.gdtcm@hotmail.com

Extended author information available on the last page of the article

\section{Introduction}

Ankylosing spondylitis is a common inflammatory rheumatic disease that affects the axial skeleton, causing characteristic inflammatory back pain and stiffness in the back and waist [1]. Axial spondyloarthritis (axSpA) consists of radiographic (traditionally known as AS) and nonradiographic (nr-axSpA) forms [2]. AS is a subtype of axSpA and presents typical radiographic manifestations. AS can cause physiological damage, disability, and neurological deafness $[3,4]$, leading to reduced quality of life (QOL) and placing a substantial financial burden on patients, their families and society [5-7]. An American study on the direct and indirect economic burden of patients with AS showed that the average direct medical costs were $\$ 2674$ during the first year, while the indirect costs were $\$ 4945$ [8]. During the 5-year study period, the cumulative cost per patient was $\$ 31,766$, 
with an average expense of $\$ 6353$ per year; of the total cost, $\$ 23,418$ was attributable to indirect costs [9].

Recent epidemiological retrospective studies have shown that the prevalence of AS in the US ranges from 0.2 to $0.55 \%$ [10]. In the Southeast Asia Pacific region, the lowest prevalence of AS was $0.01 \%$, with the highest prevalence reaching $0.49 \%$ [11]. It was also reported that the minimum and maximum AS prevalence rates in Europe were $0.08 \%$ in France and $0.86 \%$ in Germany [12], and the overall prevalence was $0.1-0.9 \%$ among Caucasians [13]. As the country with the largest population worldwide, China accounts for one-fifth of the global population. Therefore, it is of great importance to investigate the prevalence of AS in China to promote human health. However, epidemiological research on AS in China has been scarce; large samples and a wide range of national authoritative data are lacking. In 1971, John Baum found that the prevalence of AS in China was $0.22 \%$ [14, 15]. "Chinese Rheumatology", edited by Jiang Ming and published in 2004, proposed that the overall prevalence of AS was $0.3 \%$ in northeast China, $0.2-0.4 \%$ in Taiwan, and $0.01 \%$ in the northwest region. According to the review published by Wu in 2013, the overall prevalence of AS in China was $0.3 \%$ [16]. Swee performed a systematic review and included 11 cross-sectional studies investigating the prevalence of AS in China from 1994 to 2006, of which 2 studies included military populations [1]. The results showed that the prevalence of AS in the Chinese community was nearly $0.24 \%$, and the prevalence in the military was $0.23 \%$. Unfortunately, it has been years since the Swee study was published; with the rapid development of China's economy, changes in the natural environment, advances in medical technology and the enhancement of health care, the current prevalence of AS in China may differ. In addition, many single-centre cross-sectional studies on AS conducted by Chinese scholars have presented conflicting results. Thus, we performed a systematic review of epidemiological studies investigating AS conducted in China over the past 15 years to estimate the current prevalence and provide scientific data for China's health care system. The goal of this work is to provide data and theoretical support for the diagnosis and treatment of AS, as well as for clinical and basic research, by referring to the international AS diagnostic standard and past experiences in AS epidemiological investigations.

\section{Methods}

\section{Inclusion criteria}

(1) The studies were published open epidemiological studies on AS in mainland China. (2) The study subjects were recruited by sampling methods or from a healthy population in a certain region, with clear and detailed sample numbers, numbers of cases or prevalence rates. Relevant data were extracted directly from the literature or calculated with original data. (3) The studies had a cross-sectional design and the epidemiological survey data were analysed by an appropriate statistical method. (4) The studies contained specific diagnostic criteria for AS. (5) The studies were published in either English or Chinese. (6) The main purpose of this study was to study the changes in the prevalence of AS in China over the past 15 years and to understand the latest trends in the prevalence of AS in China. To this end, we wanted to compare our findings with the results of the metaanalysis published by $\mathrm{Ng} \mathrm{SC}$ on the prevalence of AS in the Chinese population before 2005 [1]. And the inclusion period was specifically limited to May 2005-May 2019.

\section{Exclusion criteria}

(1) The studies were republications or duplicate studies. (2) The study data contained obvious errors or were incomplete or unclear and relevant data could not be obtained by contacting the authors. (3) The study sample sources were those who suffered from confirmed AS, had not been diagnosed but had a high possibility of AS, or had a family history of AS. (4) The studies were reviews, case reports, clinical randomized controlled trials, etc. (5) The study publication times were not between May 2005 and May 2019.

\section{Search strategy}

Seven databases, namely, PubMed, the Cochrane Library, EMBASE, CNKI, Wanfang, VIP and CBM, were searched for epidemiological studies on AS prevalence or cross-sectional studies on AS in China. To avoid the omission of important literature, each database was searched from its establishment until May 2019. Subsequently, the literature screening included only studies published from May 2005 to May 2019 to ensure that the epidemiological data of AS prevalence in China were relatively recent. The search strategies for the seven English and Chinese databases are presented in Supplement 1.

\section{Literature screening and data extraction}

Two medical staff members who were engaged in orthopaedic clinical work not only searched the literature but also completed the preliminary and secondary screenings, strictly following the previously established inclusion and exclusion criteria. After the data were independently extracted by two researchers, a third researcher verified its accuracy. In the case of errors or differences, the third researcher and the responsible author assisted in the judgement. If there were any missing 
data in the literature, the original author was contacted by email or telephone to supplement and complete the dataset.

The main data extracted in this study included the title, first author, year of publication (year and month), type of study design, language, investigated provinces or cities, diagnostic criteria, investigation of the total sample, start-stop time, age of the surveyed group, sampling method, source of the sample, response rate, etc.

\section{Risk of bias assessment}

The Newcastle-Ottawa Scale (NOS) was used for quality assessment [17]. Three aspects were included in this scale: (1) selection of study groups (4 points); (2) ascertainment of exposure and outcome (3 points); and (3) group comparability ( 2 points). The total score is nine points. Studies with scores greater than or equal to 7 were considered to have a low risk of bias, scores of 4-6 indicated a moderate risk of bias, and scores less than 4 indicated a high risk of bias.

\section{Data synthesis and analysis}

STATA12.0 software was used to combine the prevalence rates and other relevant indicators of the included studies. According to sex, region, sample source and other indicators, subgroup analyses were conducted and visual forest plots were constructed. All subgroups (sex, region, sample source) were analysed according to our prior procedure. If there was any outcome indicator that could not be combined quantitatively, a descriptive statistical analysis was performed. Prevalence rates and $95 \%$ confidence intervals (CIs) were calculated using STATA12.0 software. In addition, for homogeneous data sets, $P>0.1$ and $I^{2}<50 \%$ were considered as the test standards. When the above two statistical conditions were met, a fixed-effect model was used for the meta-analysis, because the pooled effect sizes were relatively homogenous. If one of the above standards did not conform, the homogeneity of the pooled effect size was not ideal and the random effects model was applied. The $\alpha$ value was set as 0.05 for the meta-analysis.

For further statistical comparisons of the AS prevalence among males and females, northern and southern Chinese populations, and military and community populations in mainland China, SPSS 17. 0 software was used to perform Chi-square tests to investigate whether the three subgroup analyses were statistically significant. $P<0.05$ indicated that the difference in prevalence was statistically significant.

\section{Results}

\section{Screening results}

A total of 478 studies were obtained from the preliminary search. Of these, 123 were retained after removing irrelevant studies according to the titles and abstracts. After eliminating duplicates, 11 papers that met the inclusion and exclusion criteria were included. The literature selection flowchart and results are shown in Fig. 1.

\section{Characteristics and quality of the included studies}

The 11 included studies involved 12 provinces and 16 cities distributed in northern, southern and northwest mainland China. Three cross-sectional studies included military populations and eight studies included community populations. In total, 122,558 people were included in the cross-sectional studies, of whom 54,474 belonged to military populations and 68,084 belonged to community populations. The general characteristics and detailed data of the included studies are shown in Tables 1 and 2.

This study used the NOS to objectively score the 11 cross-sectional studies. Two studies had a score of 6 points, indicating a moderate risk of bias. Nine studies had scores greater than 7 , indicating a low risk of bias. The NOS suggested that the 11 cross-sectional studies included in this study were of high quality. The literature scores are shown in Tables 1 and 3.

\section{Meta-analysis results}

\section{Overall prevalence in China}

The 11 included cross-sectional studies reported the AS prevalence rates and sample sizes, which were combined for an effect size analysis [18-28]. The heterogeneity test revealed a $P<0.1$ and $I^{2}>50 \%$, therefore, a random effects model was adopted for the meta-analysis. The results showed that the prevalence rate of AS in mainland China was $0.29 \%$ (95\% CI $0.22 \%, 0.35 \%)$. Considering the $95 \%$ CIs among the 11 investigations, the prevalence of AS in the Chinese mainland population was $0.15 \%$ at minimum and $0.45 \%$ at maximum (Fig. 2).

\section{Prevalence of AS between males and females in China}

The respondents in the study by Wang were all male [27]. To ensure the reliability of the data, this study was not included in the subgroup analysis of the prevalence of AS by sex. Thus, ten studies were ultimately involved in the analysis 


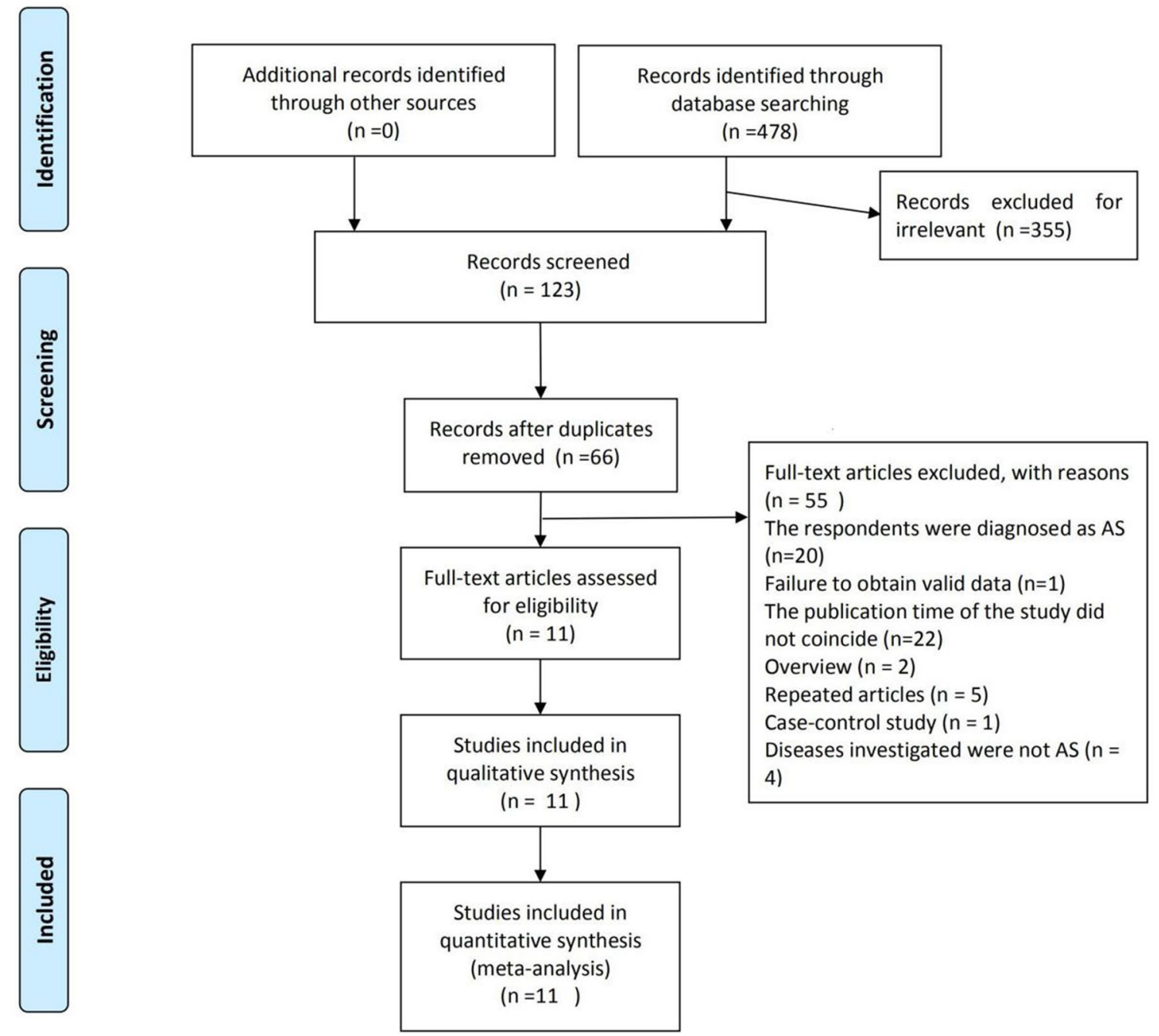

Fig. 1 Literature screening process and results

Table 1 General characteristics of the included literatures

\begin{tabular}{llllll}
\hline First author & Published time & $\begin{array}{l}\text { Language (Chi- } \\
\text { nese/English) }\end{array}$ & Research design type & Diagnostic criteria of AS & $\begin{array}{l}\text { Literature } \\
\text { quality score } \\
\text { (NOS) }\end{array}$ \\
\hline Liao et al. [18] & 2009.04 & English & Cross-sectional study & New York criteria (1984) \\
Zeng et al. [19] & 2015.09 & English & Cross-sectional study & New York criteria (1984) \\
Chen et al. [20] & 2005.10 & English & Cross-sectional study & New York criteria (1984) \\
Guan et al. [21] & 2013.08 & Chinese & Cross-sectional study & New York criteria (1984) \\
Wu et al. [22] & 2008.09 & Chinese & Cross-sectional study & New York criteria (1984) \\
Lin et al. [23] & 2015.11 & Chinese & Cross-sectional study & The criteria of the Chinese \\
& & Chinese & Cross-sectional study & New York criteria (1984) \\
Zeng et al. [24] & 2008.08 & English & Cross-sectional study & New York criteria (1984) \\
Ye et al. [25] & 2006.07 & Chinese & Cross-sectional study & New York criteria (1984) \\
Dong et al. [26] & 2006.04 & Chinese & Cross-sectional study & New York criteria (1984) \\
Wang et al. [27] & 2013.03 & Chinese & Cross-sectional study & New York criteria (1984) \\
Wang et al. [28] & 2011.08 & & & 6 \\
\hline
\end{tabular}




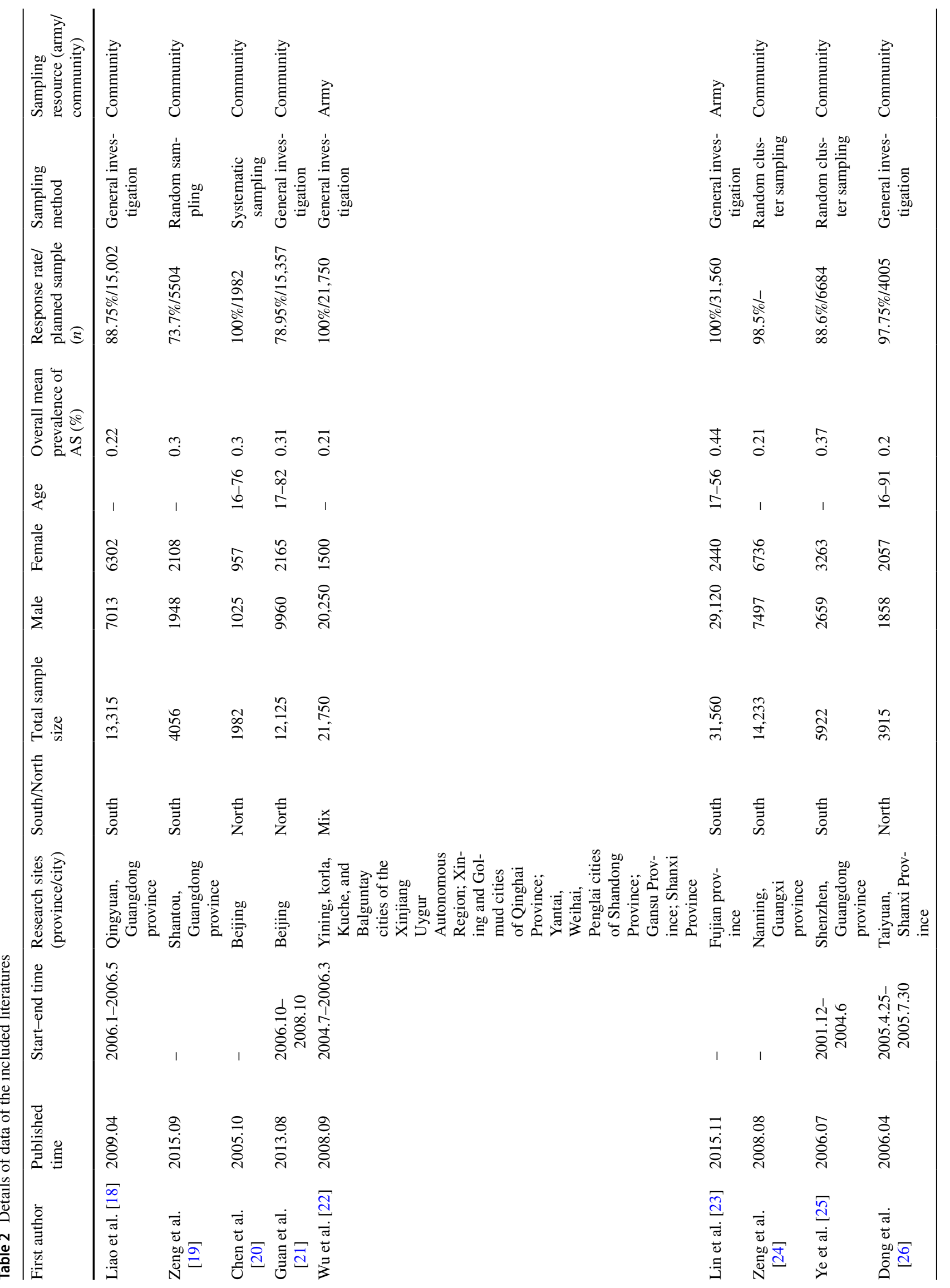




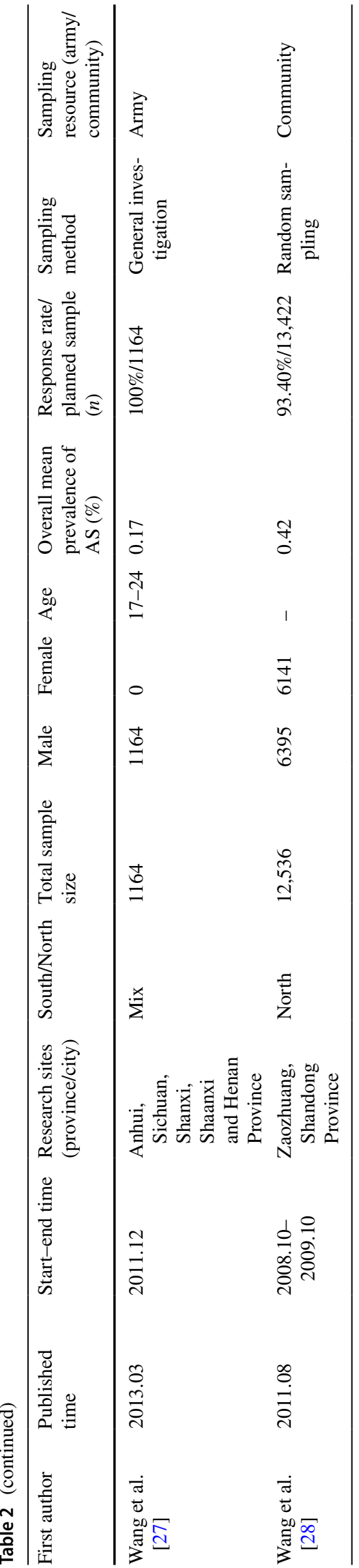

of sex differences in the prevalence of AS [18-26, 28]. A random effects model was used for meta-analysis because of heterogeneity, the results showed that the prevalence of AS in males was $0.42 \%$ (95\% CI $0.31 \%, 0.52 \%)$. After a comprehensive comparison of the $95 \%$ CI values among the ten studies, the prevalence of AS in males was found to range from 0.2 to $0.71 \%$ (Fig. 3).

Data on the prevalence of AS combined with effect size were subjected to the heterogeneity test, resulting in the selection of a random effects model. The results of the meta-analysis indicated that the AS prevalence in females was $0.15 \%$ (95\% CI $0.13 \%, 0.18 \%)$. The AS prevalence of females in mainland China was $0.09 \%$ at minimum and $0.29 \%$ at maximum after comparing the $95 \%$ CIs of the included literature (Fig. 4).

The Chi-square test showed that the prevalence of AS in males and females was significantly different $\left(X^{2}=39.975\right.$, $P<0.001)$.

\section{Prevalence of AS between southern and northern China}

To compare the difference in the AS prevalence between northern and southern China, the Qinling Mountains-Huaihe River line was considered the north-south border according to the geographical boundary of China. The sites of each included cross-sectional study were considered geographic elements (Table 2). Five studies [18, 19, 23-25] were conducted in the southern region and four [20,21, 26, 28] were conducted in the northern region. Since the research sites of two papers (Wang L and Wu ZB) spanned the northwest, south and north of China, an accurate separation of the various provinces was difficult, thus, these two studies were not included in this particular subanalysis [22, 27].

There was high heterogeneity in the meta-analysis of AS prevalence in both the north and south, so random effects models were adopted. The results showed that the prevalence of AS was $0.31 \%$ in both the north and south, and the $95 \%$ CIs were $0.2 \%$ and $0.42 \%$ and $0.21 \%$ and $0.40 \%$, respectively. Considering the $95 \%$ CIs of the north and south, the lowest prevalence rates of AS in southern and northern China were $0.2 \%$ and $0.19 \%$, and the highest were $0.45 \%$ and $0.43 \%$, respectively (Figs. 5,6 ).

There was no significant difference in the prevalence of AS in the north and south according to the Chi-square test $\left(X^{2}=0.054, P=0.816>0.005\right)$.

\section{Prevalence of AS between military and community populations in China}

Among the 11 studies included in the analysis, 3 [22, 23, 27] included Chinese military populations, and the remaining 8 [18-21, 24-26, 28] included community populations. The effect sizes of each group were combined and the 
Table 3 Newcastle-Ottawa Scale for risk of bias assessment of cohort studies included in the meta-analysis

\begin{tabular}{|c|c|c|c|c|c|c|c|c|c|}
\hline \multirow[t]{2}{*}{ Study } & \multicolumn{4}{|l|}{ Selection } & \multirow[t]{2}{*}{ Comparability } & \multicolumn{3}{|l|}{ Outcome } & \multirow[t]{2}{*}{ Overall } \\
\hline & $\begin{array}{l}\text { Representa- } \\
\text { tiveness of } \\
\text { exposed } \\
\text { cohort }\end{array}$ & $\begin{array}{l}\text { Selection of } \\
\text { nonexposed }\end{array}$ & $\begin{array}{l}\text { Ascertain- } \\
\text { ment of } \\
\text { exposure }\end{array}$ & $\begin{array}{l}\text { Outcome not } \\
\text { present at } \\
\text { start }\end{array}$ & & $\begin{array}{l}\text { Assessment } \\
\text { of outcome }\end{array}$ & $\begin{array}{l}\text { Adequate } \\
\text { Follow-up } \\
\text { length }\end{array}$ & $\begin{array}{l}\text { Adequacy } \\
\text { of follow- } \\
\text { up }\end{array}$ & \\
\hline Liao et al. [18] & $\star$ & $\star$ & $\star$ & $\star$ & $\star \star$ & $\star$ & $\star$ & $\star$ & 9 \\
\hline $\begin{array}{l}\text { Zeng et al. } \\
\text { [19] }\end{array}$ & $\star$ & $\star$ & $\star$ & $\star$ & $\star \star$ & tro & $\star$ & $\star$ & 8 \\
\hline $\begin{array}{l}\text { Chen et al. } \\
\text { [20] }\end{array}$ & $\star$ & $\star$ & $\star$ & $\star$ & $\star \star$ & 㶦 & $\star$ & $\star$ & 8 \\
\hline $\begin{array}{l}\text { Guan et al. } \\
\text { [21] }\end{array}$ & $\star$ & $\star$ & $\star$ & $\star$ & $\star \star$ & $\star$ & $\star$ & $\star$ & 9 \\
\hline Wu et al. [22] & $\star$ & $\star$ & $\star$ & $\star$ & $\star$ & $\star$ & $\star$ & $\star$ & 8 \\
\hline Lin et al. [23] & $\star$ & $\star$ & $\star$ & $\star$ & $\star$ & $\star$ & $\star$ & $\star$ & 8 \\
\hline $\begin{array}{l}\text { Zeng et al. } \\
\text { [24] }\end{array}$ & $\star$ & 弐 & $\star$ & $\star$ & $\star$ & tr & $\star$ & $\star$ & 6 \\
\hline Ye et al. [25] & $\star$ & $\star$ & $\star$ & $\star$ & $\star \star$ & $\star$ & $\star$ & $\star$ & 9 \\
\hline $\begin{array}{l}\text { Dong et al. } \\
\text { [26] }\end{array}$ & $\star$ & $\star$ & $\star$ & $\star$ & $\star \star$ & $\star$ & $\star$ & $\star$ & 9 \\
\hline $\begin{array}{l}\text { Wang et al. } \\
\text { [27] }\end{array}$ & $\hat{x}$ & 㶦 & $\star$ & $\star$ & $\star$ & $\star$ & $\star$ & $\star$ & 6 \\
\hline $\begin{array}{l}\text { Wang et al. } \\
\text { [28] }\end{array}$ & $\star$ & $\star$ & $\star$ & $\star$ & $\star$ & $\star$ & $\star$ & $\star$ & 8 \\
\hline
\end{tabular}

$\star$, score of $1 ; \star \star$, score of 2 ; $九$, score of 0

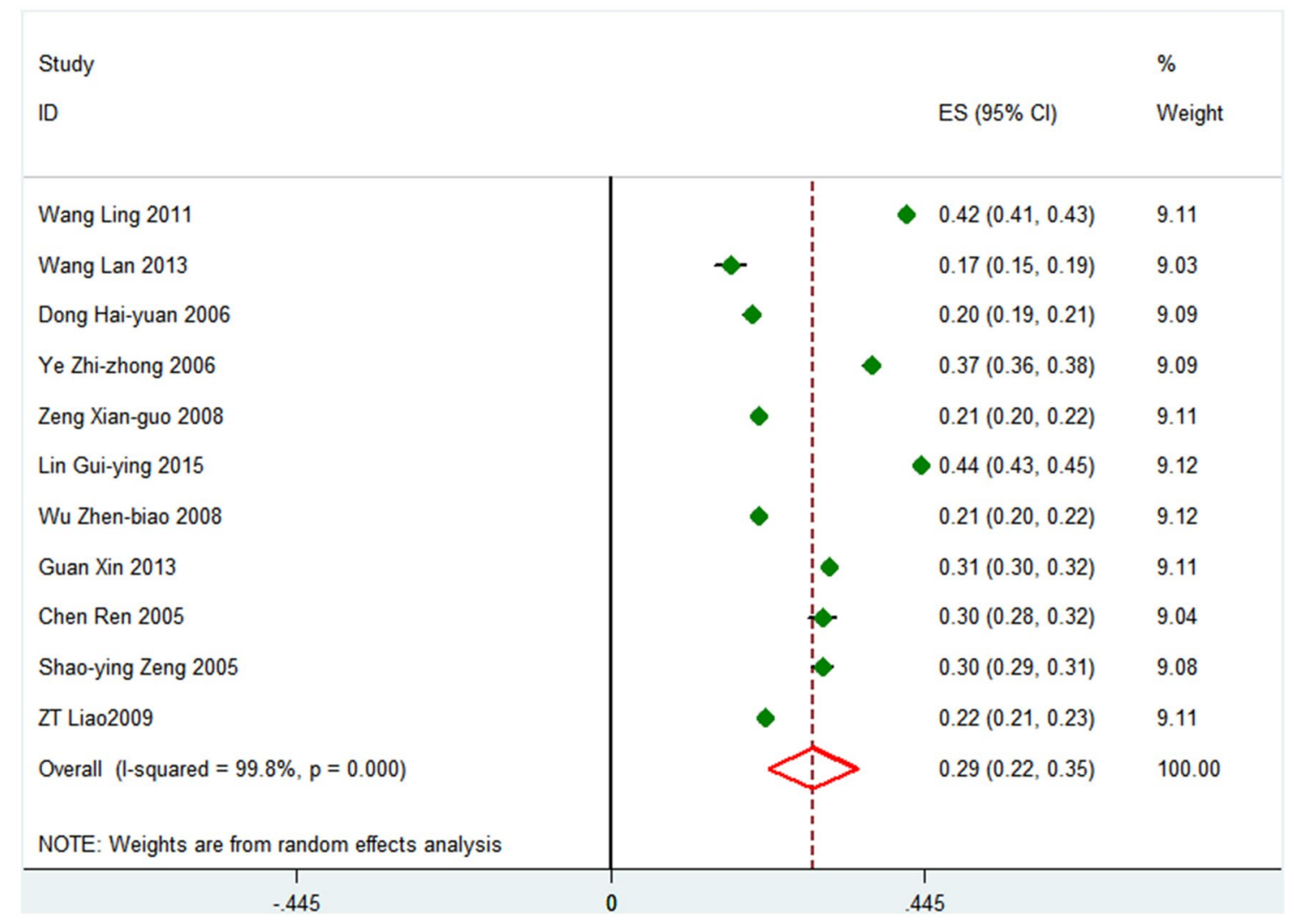

Fig. 2 Meta-analysis of the total prevalence of AS in China 
Study

ID
$\%$

ES $(95 \% \mathrm{Cl}) \quad$ Weight

\begin{tabular}{|c|c|c|c|}
\hline Wang Ling 2011 & & $0.70(0.69,0.71)$ & 10.01 \\
\hline Dong Hai-yuan 2006 & $\bullet$ & $0.27(0.25,0.29)$ & 9.99 \\
\hline Ye Zhi-zhong 2006 & & $0.68(0.66,0.70)$ & 10.00 \\
\hline Zeng Xian-guo 2008 & $\bullet$ & $0.29(0.28,0.30)$ & 10.01 \\
\hline Lin Gui-ying 2015 & & $0.47(0.46,0.48)$ & 10.02 \\
\hline Wu Zhen-biao 2008 & $\bullet$ & $0.21(0.20,0.22)$ & 10.02 \\
\hline Guan Xin 2013 & $\bullet$ & $0.34(0.33,0.35)$ & 10.02 \\
\hline Chen Ren 2005 & & $0.49(0.46,0.52)$ & 9.94 \\
\hline Shao-ying Zeng 2005 & & $0.46(0.44,0.48)$ & 9.98 \\
\hline ZT Liao 2009 & $\bullet$ & $0.26(0.25,0.27)$ & 10.01 \\
\hline Overall $(1-$ squared $=99.9 \%, p=0.000)$ & & $0.42(0.31,0.52)$ & 100.00 \\
\hline NOTE: Weights are from random effects analysis & & & \\
\hline-711 & & .711 & \\
\hline
\end{tabular}

Fig. 3 Meta-analysis of the prevalence of AS in Chinese males

Study

ID
$\%$

ES $(95 \% \mathrm{Cl}) \quad$ Weight

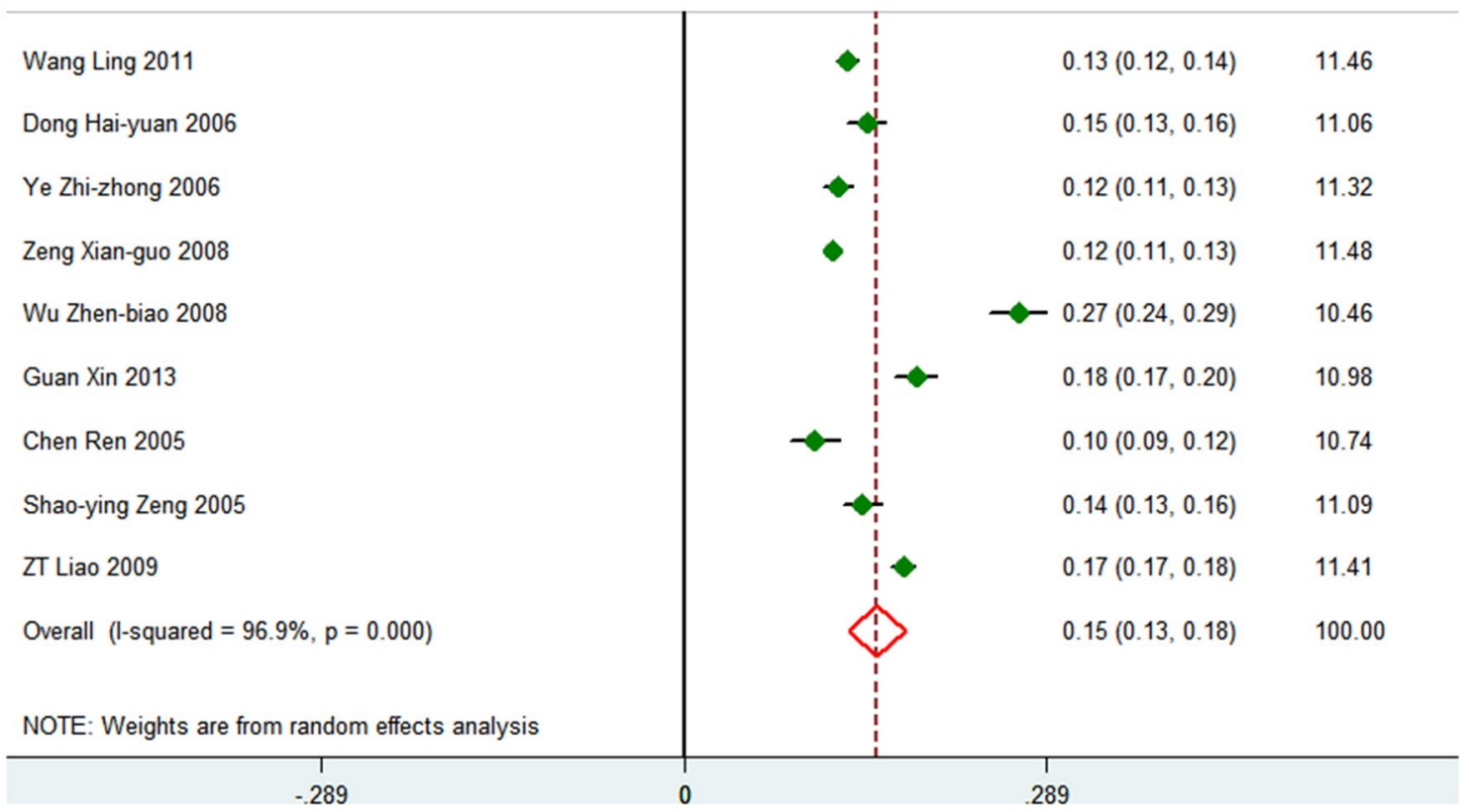

Fig. 4 Meta-analysis of the prevalence of AS in Chinese females 
Study

ID
$\%$

ES $(95 \% \mathrm{Cl})$
Weight

\begin{tabular}{|c|c|c|c|c|}
\hline Ye Zhi-zhong 2006 & & $\bullet$ & $0.37(0.36,0.38)$ & 19.98 \\
\hline Zeng Xian-guo 2008 & - & & $0.21(0.20,0.22)$ & 20.02 \\
\hline Lin Gui-ying 2015 & & & $\bullet 0.44(0.43,0.45)$ & 20.02 \\
\hline Shao-ying Zeng 2005 & & & $0.30(0.29,0.31)$ & 19.96 \\
\hline ZT Liao 2009 & $\bullet$ & & $0.22(0.21,0.23)$ & 20.02 \\
\hline Overall $(1-$ squared $=99.9 \%, p=0.000)$ & & & $0.31(0.20,0.42)$ & 100.00 \\
\hline NOTE: Weights are from random effects analysis & & & & \\
\hline-.445 & & & .445 & \\
\hline
\end{tabular}

Fig. 5 Meta-analysis of the prevalence of AS in southern China

Study

ID
$\%$

ES $(95 \% \mathrm{Cl})$

Weight

\begin{tabular}{|c|c|c|c|}
\hline Wang Ling 2011 & & $0.42(0.41,0.43)$ & 25.07 \\
\hline Dong Haiyuan 2006 & $\bullet$ & $0.20(0.19,0.21)$ & 25.01 \\
\hline Guan Xin 2013 & & $0.31(0.30,0.32)$ & 25.08 \\
\hline Chen Ren 2005 & & $0.30(0.28,0.32)$ & 24.83 \\
\hline Overall $(1-$ squared $=99.7 \%, p=0.000)$ & & $0.31(0.21,0.40)$ & 100.00 \\
\hline NOTE: Weights are from random effects analysis & & & \\
\hline
\end{tabular}

Fig. 6 Meta-analysis of AS prevalence in North China 
meta-analysis indicated that heterogeneity existed in both groups. The results showed that the prevalence of AS in Chinese military populations was $0.27 \%$ (95\% CI: $0.09 \%$, $0.45 \%$ ), ranging from $0.15 \%$ to $0.45 \%$ (Fig. 7 ). On the other hand, the Chinese community population had a prevalence of $0.29 \%$ (95\% CI $0.23 \%, 0.35 \%$ ), with $0.43 \%$ representing the highest prevalence and $0.19 \%$ representing the lowest prevalence (Fig. 8).

The difference in the prevalence of AS between military and community populations was not significantly different according to the Chi-square test $\left(X^{2}=2.484\right.$, $P=0.115>0.005$ ).

\section{Discussion}

This study was the second quantitative systematic review of AS prevalence in China and serves to update the data published 13 years ago by Swee Cheng $\mathrm{Ng}$ [1]. The results showed that the general prevalence of AS in mainland China was $0.29 \%$ over the past 15 years. The results of the present study showed that the prevalence rates are higher than $0.24 \%$ in the community population and $0.23 \%$ in the military population reported in Swee's 2007 research [1] and exhibit an increasing tendency. The global average prevalence of AS is $0.1-1 \%$ [4, 29, 30]. The prevalence rates of AS in China are in the relatively low range compared to those worldwide, for example, the rates reported in the current study are lower than those reported in Norway $(1.1-1.4 \%)$ and in indigenous Alaskan populations $(0.4 \%)$. The prevalence of AS in males was found to be $0.42 \%$, which is 2.8 times higher than that in females, resulting in a statistically significant difference between the sexes. This finding is consistent with the general AS epidemiological finding that males have a higher prevalence than females $[1,4,31]$. The prevalence of AS in both the southern and northern populations of mainland China in this study was $0.31 \%$, indicating no significant difference according to geographical region. In terms of sample populations, the prevalence rates of AS in the military and community populations were $0.27 \%$ and $0.29 \%$, respectively, which were both higher than those reported in Swee's study in 2007 (0.23\% and 0.24\%, respectively). Due to the specificity of soldiers' positions and job duties, the departments of the Chinese government should emphasize a physical examination at enlistment. In both the military and community populations, the prevalence of AS has shown an increasing trend over the past 15 years. This increase may be due to advancement in our diagnostic capabilities, contributing to an increase in the rate of AS diagnoses, or to changes in our lifestyle habits, natural and social environments, etc. These factors should be the focus of epidemiological studies investigating AS in the future.

Based on a systematic review of the epidemiological literature and by referring to the latest international AS research, this paper summarizes the characteristics of AS

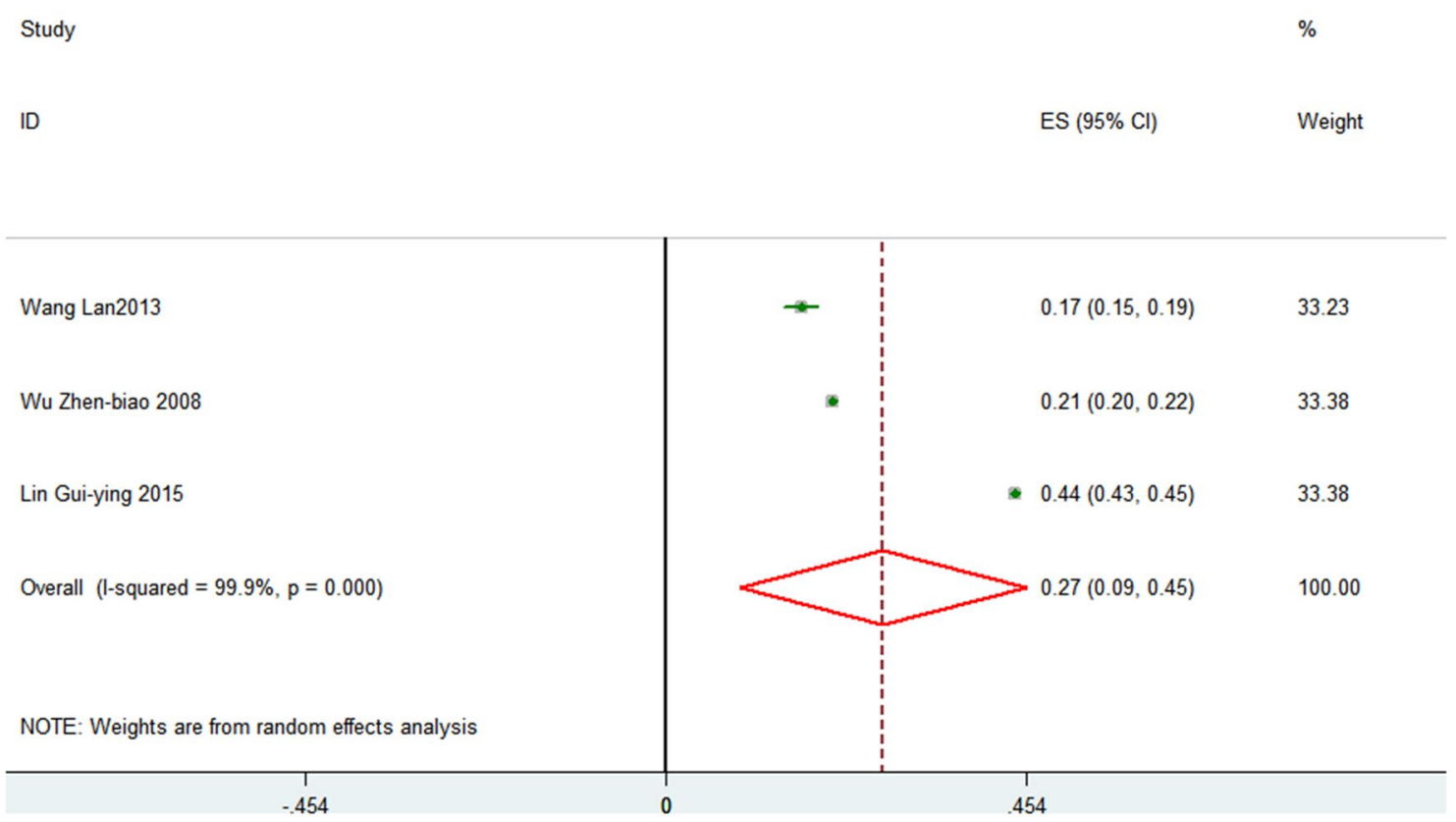

Fig. 7 Meta-analysis of the prevalence of AS in the Chinese Army 


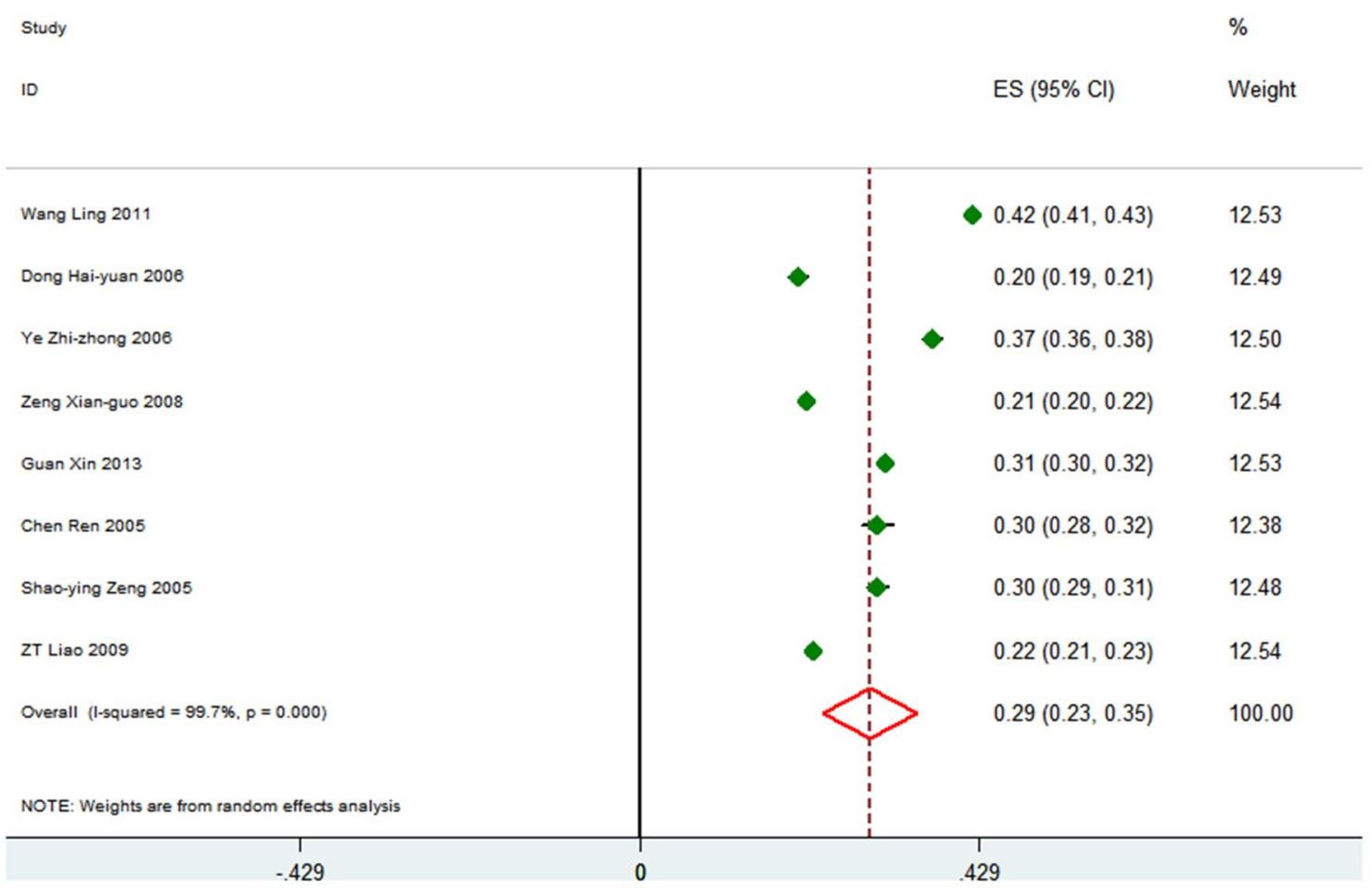

Fig. 8 Meta-analysis of the prevalence of AS in Chinese communities

epidemiological investigations in China and provides suggestions for future research, as follows:

1. The sample populations in cross-sectional AS studies conducted in mainland China were sufficiently large, but the representativeness of these study populations was insufficient. The NOS results show that the 11 cross-sectional studies included in this paper are of high quality but also possess some limitations. The epidemiological studies on AS were mostly single-centre studies; among the provincial- and municipal-level investigations, the studies were often concentrated in certain communities. The lack of random sampling data from multiple sites may have affected the accuracy and representativeness of AS prevalence data obtained from provinces and cities.

2. Epidemiological AS surveys have mainly focused on the southern, northern and northwest regions of China. Epidemiological data from the Qinghai-Tibet Plateau are scarce. It has been suggested that researchers strengthen AS epidemiological investigations in the Qinghai-Tibet Plateau.

3. There was a large difference between the sexes in military populations, but the sex ratio in community populations was relatively balanced. In this study, three studies on the prevalence of AS in military populations and eight studies in community populations were included. The total sample amounts in the military and community populations were 54,474 and 68,084 patients, respectively. A total of 50,534 and 38,355 patients were male, while 3,940 and 29,729 patients were female, respectively. Considering the impact of sex differences on total prevalence in the studies, it is suggested that AS epidemiology researchers combine multiple sampling methods, such as stratified sampling, systematic sampling, random sampling, etc., for investigation programmes.

4. Information on the age of the respondents was not often reported, therefore, the study of the pathogenesis characteristics and patterns of AS at different ages was difficult. Among the 11 included studies, only 4 [18, 22, 26, 28 ] reported the age characteristics of the respondents in detail,however, there were different standards of age classifications. To better investigate the age characteristics of AS onset and standardize age information in AS epidemiological surveys, it is suggested that researchers use the above age-related onset patterns or include important age stratifications, such as ages 17 and 40 .

5. The factors of AS epidemiology in China were relatively singular and mainly included prevalence rates, sex differences and complications. In this study, the crosssectional studies of AS mainly focused on prevalence. However, data on the changes in QOL, economic costs 
and employment of AS patients under medical care were difficult to obtain and hinder the decision-making ability of the medical health system, government and welfare institutions. It is difficult to collect data on the QOL of AS patients in the real world due to the strict implementation criteria of randomized clinical trials (RCTs). Thus, data on the QOL of AS patients hold great value in epidemiological studies [3]. Therefore, we recommend that relevant Chinese researchers should increase data collection for such indicators in subsequent epidemiological studies.

Nevertheless, several limitations were unavoidable and should be mentioned. First, the time period for inclusion in this study was from May 2005 to May 2019. Thus, crosssectional studies before 2005 were not included, which may have resulted in some related studies being omitted. Second, the cross-sectional study sites included in this meta-analysis were mainly concentrated in southern, northern, and northwestern China and lacked prevalence data for southwestern and eastern China. Third, the overall prevalence and heterogeneity of each subgroup analysis are large, which may be limited by the shortcomings related to single-rate metaanalyses, and often, the source of heterogeneity cannot be found through sensitivity analysis. Therefore, we believe that there are several possibilities to explain this large heterogeneity. (1) The survey period of each cross-sectional research institute is different and the scale of the diagnostic criteria is not the same, even though the diagnostic criteria of the 11 studies included in this study are relatively uniform. (2) The source of the study population is different, as the populations are from different geographical locations across China, and the sample is insufficiently representative. (3) The information available in the included literature was limited; some studies did not provide comprehensive or specific data on sex, age, course of disease, etc., for subgroup analysis. Therefore, this study could not perform meta-regression analysis based on these variables to further identify sources of heterogeneity.

\section{Conclusions}

In summary, this study found that the prevalence of AS was $0.29 \%$ in China during the past 15 years and has shown an increasing tendency. The prevalence of AS in males was 2.8 times higher than that in females. There were no obvious differences in the prevalence of AS between the military and community populations or between southern and northern China.

In view of the rising trend of AS prevalence in the past 15 years in China, health care departments of the Chinese government should not only strengthen the scientific popularization of AS to motivate the development of early detection, diagnosis and treatment strategies but also establish medical policies related to AS.

In addition, epidemiological researchers need to develop more complete and scientific research programmes with advanced diagnostic and treatment standards, survey tools and evaluation indicators to provide more effective, scientific and authoritative epidemiological data for the prevention and treatment of AS in China.

Acknowledgements We thank American Journal Experts for linguistic assistance during the preparation of this manuscript.

Author contributions $\mathrm{JZ}, \mathrm{CH}$ and $\mathrm{HH}$ had the original idea for the study and proposed the study design. JP, WY and LZ conducted the literature search, screened and selected the studies initially identified. ML, HH and GL read and evaluated the quality of the studies included. $\mathrm{JZ}$ and $\mathrm{CH}$ conducted the meta-analysis. Authors $\mathrm{JL}$ and $\mathrm{JZ}$ contributed in drafting the work, and all other authors revised it critically for important intellectual content. All authors approved the final version of the manuscript to be published. All authors agree to be accountable for all aspects of the work in ensuring that questions related to the accuracy or integrity of any part of the work are appropriately investigated and resolved.

Funding This work was supported by the National Natural Science Foundation of China (no. 81873314, no. 81974574), the Project of Guangdong Provincial Department of Finance (no. [2014]157, no. [2018]8), the China Postdoctoral Science Foundation (no. 2018M633036), the Medical Science Research Foundation of Guangdong Province (no. B2019091), the Project of Administration of Traditional Chinese Medicine of Guangdong Province (no. 20201129), the Key scientific research platforms and research projects of universities in Guangdong Province (no. 2018KQNCX041), and the Science and Technology Research Project of Guangdong Provincial Hospital of Chinese Medicine (no. YN2019ML08, no. YK2013B2N19, and no. YN2015MS15).

Availability of data and material The data can be requested from the corresponding author.

\section{Compliance with ethical standards}

Conflict of interest The authors declare that they have no conflict of interest.

Ethics approval and consent to participate Not applicable.

Consent for publication All authors agree to publish in Rheumatology International.

Open Access This article is licensed under a Creative Commons Attribution 4.0 International License, which permits use, sharing, adaptation, distribution and reproduction in any medium or format, as long as you give appropriate credit to the original author(s) and the source, provide a link to the Creative Commons licence, and indicate if changes were made. The images or other third party material in this article are included in the article's Creative Commons licence, unless indicated otherwise in a credit line to the material. If material is not included in the article's Creative Commons licence and your intended use is not 
permitted by statutory regulation or exceeds the permitted use, you will need to obtain permission directly from the copyright holder. To view a copy of this licence, visit http://creativecommons.org/licenses/by/4.0/.

\section{References}

1. Ng SC, Liao Z, Yu DT et al (2007) Epidemiology of spondyloarthritis in the People's Republic of China: review of the literature and commentary. Semin Arthritis Rheum 37(1):39-47. https://doi.org/10.1016/j.semarthrit.2007.01.003

2. Garrido-Cumbrera M, Poddubnyy D, Gossec L et al (2019) The European Map of axial spondyloarthritis: capturing the patient perspective-an analysis of 2846 patients across 13 countries. Curr Rheumatol Rep 21(5):19. https://doi.org/10.1007/s1192 6-019-0819-8

3. Sieper J, Poddubnyy D (2017) Axial spondyloarthritis. Lancet 390(10089):73-84. https://doi.org/10.1016/S0140 $-6736(16) 31591-4$

4. Sajal A, Amit K, Rakesh S et al (2019) Hearing loss in ankylosing spondylitis. Int J Rheum Dis 22(7):1202-1208. https://doi. org/10.1111/1756-185X.13560

5. Rosenbaum JT, Pisenti L, Park Y et al (2019) Insight into the quality of life of patients with ankylosing spondylitis: real-world data from a US-based life impact survey. Rheumatol Ther 6(3):353367. https://doi.org/10.1007/s40744-019-0160-8

6. Boonen A, Mau W (2009) The economic burden of disease: comparison between rheumatoid arthritis and ankylosing spondylitis. Clin Exp Rheumatol 27(4 Suppl 55):S112-S117

7. Zhao SS, Radner H, Siebert S et al (2019) Comorbidity burden in axial spondyloarthritis: a cluster analysis. Rheumatology (Oxford) 58(10):1746-1754. https://doi.org/10.1093/rheumatology/kez119

8. Palla I, Trieste L, Tani C et al (2012) A systematic literature review of the economic impact of ankylosing spondylitis. Clin Exp Rheumatol 30(4 Suppl 73):S136-S141

9. Ward MM (2002) Functional disability predicts total costs in patients with ankylosing spondylitis. Arthritis Rheum 46(1):223231. https://doi.org/10.1002/1529-0131(200201)46:1\%3c223 :AID-ART498\%3e3.0.CO;2-\#

10. Reveille JD, Weisman MH (2013) The epidemiology of back pain, axial spondyloarthritis and HLA-B27 in the United States. Am J Med Sci 345(6):431-436. https://doi.org/10.1097/maj.0b013 e318294457f

11. Zlatkovic-Svenda M, Stojanovic R, Sipetic-Grujicic S et al (2019) Prevalence of spondyloarthritis and its subtypes - are they really comparable? Srp Arh Celok Lek 147(3-4):235-242. https://doi. org/10.2298/SARH180110009Z

12. Braun J, Bollow M, Remlinger $G$ et al (1998) Prevalence of spondylarthropathies in HLA-B27 positive and negative blood donors. Arthritis Rheum 41(1):58-67. https://doi.org/10.1002/15290131(199801)41:1\%3c58:AID-ART8\%3e3.0.CO;2-G

13. Jiang M (2004) Chinese rheumatology. Huaxia Publishing House, Beijing, pp 10-43

14. Baum J, Ziff M (1971) The rarity of ankylosing spondylitis in the black race. Arthritis Rheum 14(1):12-18. https://doi.org/10.1002/ art. 1780140103

15. Yao-Jun X, Sheng-Ming D (2009) Prevalence of rheumatic diseases and disability in China. Rheumatol Int 29(5):481-490. https ://doi.org/10.1007/s00296-008-0809-z

16. Wu S, Duan Z, Pan F (2013) Progress in epidemiological study of ankylosing spondylitis. Acta Universitatis Medicinalis Anhui 48(08), 988-992. 10.19405/j.cnki.issn1000-1492.2013.08.037.
17. Wells GA, Shea B, O'Connell D et al (2020) The NewcastleOttawa Scale (NOS) for assessing the quality of nonrandomized studies in meta-analyses. https://www.ohri.ca/programs/clini cal_epidemiology/oxford.htm. Accessed 21 Jan 2020

18. Liao ZT, Pan YF, Huang JL et al (2009) An epidemiological survey of low back pain and axial spondyloarthritis in a Chinese Han population. Scand J Rheumatol 38(6):455-459. https://doi. org/10.3109/03009740902978085

19. Zeng S, Gong Y, Zhang Y et al (2015) Changes in the prevalence of rheumatic diseases in Shantou, China, in the past three decades: a COPCORD Study. PLoS One 10(9):e138492. https://doi. org/10.1371/journal.pone.0138492

20. Chen R, Du L, Lin Q et al (2005) Epidemiological study on spondyloarthropathy in 1982 workers and their relatives residing in Beijing urban district. Chin J Clin Rehabil 9(39):148-149. https ://doi.org/10.3321/j.issn:1673-8225.2005.39.003

21. Guan X, Wang K, Han S et al. (2013) Clinical characteristics of male and female spondyloarthritis in Shougang, Beijing. Beijing Med 35(08), 727-728. 10.15932/j.0253-9713.2013.08.019.

22. Wu Z, Zhu P, Wang $\mathrm{H}$ et al (2008) Epidemiological investigation of rheumatoid arthritis and seronegative spondlarthritis in Chinese armed forces. J Fourth Mil Med Univ 18:1696-1699. https://doi. org/10.3321/j.issn:1000-2790.2008.18.017

23. Lin G, Zeng H, Feng X et al (2015) Epidemiological investigation of rheumatism disease on southeast coastal soldiers and analysis of retirement due to illness. Mil Med J Southeast China 17(06):604606. https://doi.org/10.3969/j.issn.1672-271X.2015.06.013

24. Zeng X, Chen B, Zeng F et al (2008) Epidemiological survey of common rheumatic in Guangxi Nanning Zhuang population. J Pract Med 8:1432-1434. https://doi.org/10.3969/j. issn.1006-5725.2008.08.074

25. Ye Z, Zhuang J, Wang X et al (2006) Epidemiological survey on prevalence of ankylosing spondylitis in 5922 Shenzhen inhabitants. Chin J Clin Rehabil 10(28):159-162. https://doi. org/10.3321/j.issn:1673-8225.2006.28.008

26. Dong H, Zang C, Zhang A et al (2006) Epidemiological study of seronegative spondyloarthropathies in Taiyuan. Chin Remedies Clinice 6(4):262-265. https://doi.org/10.3969/j. issn.1671-2560.2006.04.007

27. Wang L, Yuan H, Li H et al (2013) Epidemiological investigation of ankylosing spondylitis in recruits of one department of People's Armed Police Forces. J Log Univ CAPF (Medical Science) 22(03):220-221. https://doi.org/10.3969/j. issn.2095-3720.2013.03.022

28. Ling W, Hua Z, Xin-mei Ma et al (2011) Epidemiological investigation of spondyloarthropathy in Zaozhuang. J Med Forum 32(15): 19-21

29. Trontzas P, Andrianakos A, Miyakis S (2005) Seronegative spondyloarthropathies in Greece: a population-based study of prevalence, clinical pattern, and management. The ESORDIG study. Clin Rheumatol 24(6):583-589. https://doi.org/10.1007/s1006 7-005-1106-9

30. De Angelis R, Salaffi F, Grassi W (2007) Prevalence of spondyloarthropathies in an Italian population sample: a regional community-based study. Scand J Rheumatol 36(1), 14-21. https:// doi. org/10.1080/03009740600904243.

31. Alper U, Ilhan S (2017) Ankylosing spondylitis and balance. Eurasian J Med 49(3):207-210. https://doi.org/10.5152/eurasianjm ed.2017.17116

Publisher's Note Springer Nature remains neutral with regard to jurisdictional claims in published maps and institutional affiliations. 


\section{Affiliations}

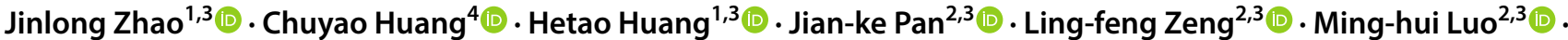 Gui-hong Liang ${ }^{2,3}$ (D) Wei-yi Yang ${ }^{2,3}$ (D) Jun Liü Lid $^{2,3}$}

Jinlong Zhao

zhaojinlong41@163.com

Chuyao Huang

huangchuyao147@163.com

Hetao Huang

ynhtsmile@126.com

Jian-ke Pan

panjianke0324@126.com

Ling-feng Zeng

lingfengzeng0202@163.com

Ming-hui Luo

741025246@qq.com

Gui-hong Liang

liangguihonghe@163.com
Wei-yi Yang

czyangwy@163.com

1 The Second School of Clinical Medical Sciences, Guangzhou University of Chinese Medicine, Guagnzhou 510405, China

2 The Second Affiliated Hospital, Guangzhou University of Chinese Medicine (Guangdong Province Hospital of Traditional Chinese Medicine), Guangzhou 510120, China

3 Guangdong Academy of Traditional Chinese Medicine, Research Team on Bone and Joint Degeneration and Injury, Guangzhou 510120, China

4 Clinical Medical College of Acupuncture and Rehabilitation, Guangzhou University of Chinese Medicine,

Guagnzhou 510405, China 